\title{
CLASSIFICATION OF CYCLONE TRACKS OVER APENNINES AND ADRIATIC SEA
}

\author{
K. Horvath ${ }^{1}$, Y.-L. Lin ${ }^{2}$, B. Ivančan-Picek ${ }^{1}$ \\ ${ }^{1}$ Meteorological and Hydrological Service, Zagreb, Croatia \\ ${ }^{2}$ North Carolina State University, Raleigh, North Carolina, U.S.A. \\ E-mail: horvath@cirus.dhz.hr
}

\begin{abstract}
Cyclones that appear in the basin of Adriatic Sea strongly influence the climate and weather conditions in the area. It is therefore crucial to classify the different cyclone types in the area since it enhances the understanding and prediction of the related phenomena. In this study, based on the analysis of four year (2002 - 2005) operational ECMWF T511 dataset, we classify various types of cyclone tracks as well as isolate the mesocyclogenesis areas in the vicinity of Adriatic basin. Our analysis indicates that four types of cyclogenesis over the Adriatic Sea can be identified: (1) Type A: cyclones connected with pre-existing Genoa cyclones. Two subcategories are found: (I) continuous track: Genoa cyclones crossing over the Apennines to the Adriatic Sea and (II) discontinuous track: new surface cyclones generated over the Adriatic Sea under the influence of a parent cyclone generated in the Gulf of Genoa (Genoa cyclones) but blocked by the Apennines; (2) Type B: cyclones developed in situ over the Adriatic Sea without any connections with other pre-existing cyclones in the surrounding area; (3) Type AB: mixed types A and B cyclones. In this type of cyclones, two cyclones co-exist and stride over the Apennines (twin or eyeglasses cyclones); and (4) Type C: cyclones moving from Mediterranean Sea, but not from the Gulf of Genoa (non-Genoa cyclones). Two subcategories are found: (I) continuous track: a non-Genoa cyclone is able to cross over the Apennines to the Adriatic Sea continuously and (II) discontinuous track: a non-Genoa cyclone is blocked by the Apennines and a new surface cyclone is generated over the Adriatic Sea.
\end{abstract}

Keywords: cyclone classification, Adriatic Sea, cyclone tracks

\section{INTRODUCTION}

The Adriatic Sea is a mesoscale NW-SE elongated basin in the central Mediterranean Sea, which is approximately $200 \mathrm{~km}$ wide and $1200 \mathrm{~km}$ long, almost entirely enclosed by high mountains - Apennines to the west and southwest, Alps to the north and Dinaric Alps on the east and southeast (Fig. 1). Apart from the usually mild climate, cyclonic activity in the Adriatic provides a trigger mechanism for a range of extreme weather phenomena, such as local downslope windstorms Bora (known as "Bura" in Croatia) and heavy orographic precipitation. Therefore, investigations and possible clustering of these processes are of a great regional importance.

Due to the meso- $\beta$ scales of the Adriatic basin and its surrounding complex terrain, cyclogenesis in the

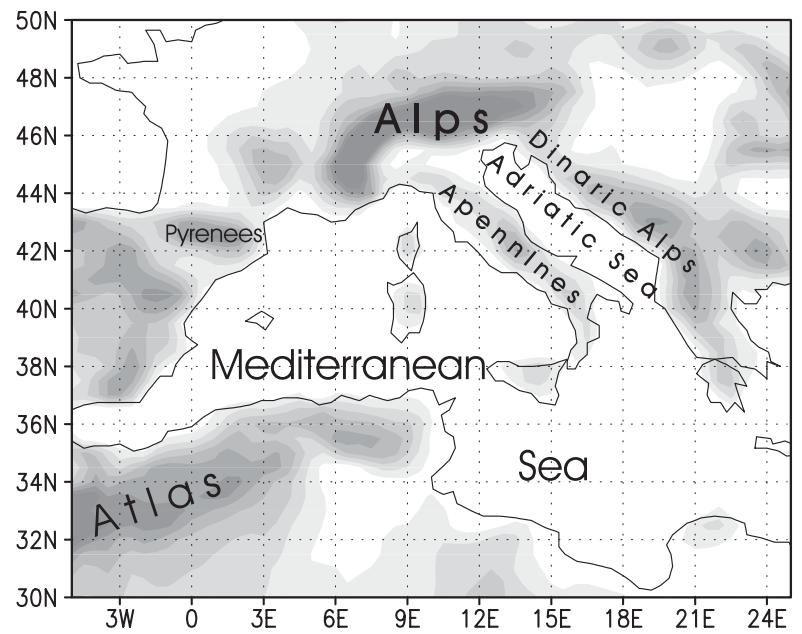

Adriatic Sea was traditionally poorly detected by subjective synoptic analysis. Despite the encouraging attempts (e.g. Radinović, 1965), traditional sub-synoptic analysis suffered from the limited data availability. Recent objective studies (e.g. Trigo et al., 1999, Campins et al., 2006) usually focused on the larger scales phenomena, since the objective detection and tracking algorithms are yet not a reliable tool in high quality identification of meso- $\beta$ cyclone activity. For these reasons, the authors chose to conduct a subjective analysis fully devoted to the cyclonic activity in the Adriatic basin, using ECMWF T511 operational analysis data for the 4-yr period (2002-2005).

Figure 1: The western and middle Mediterranean with sites of interest mentioned in the text. The area corresponds to a ECMWF T511 resolution model orography in the domain. The terrain contour interval is $200 \mathrm{~m}$ starting from $200 \mathrm{~m}$. 


\section{CLASSIFICATION OF ADRIATIC CYCLONES}

The subjective analysis was based on the operational forecasters' experience of the Meteorological and Hydrological Service of Croatia. The analysis included additional subjective vorticity as well as the objective mean sea level pressure (MSLP) intensity and cyclone duration guidance that included $2 \mathrm{hPa}$ closed MSLP isobar in at least 6 hours (two subsequent analysis periods) for the affirmative cyclone identification.
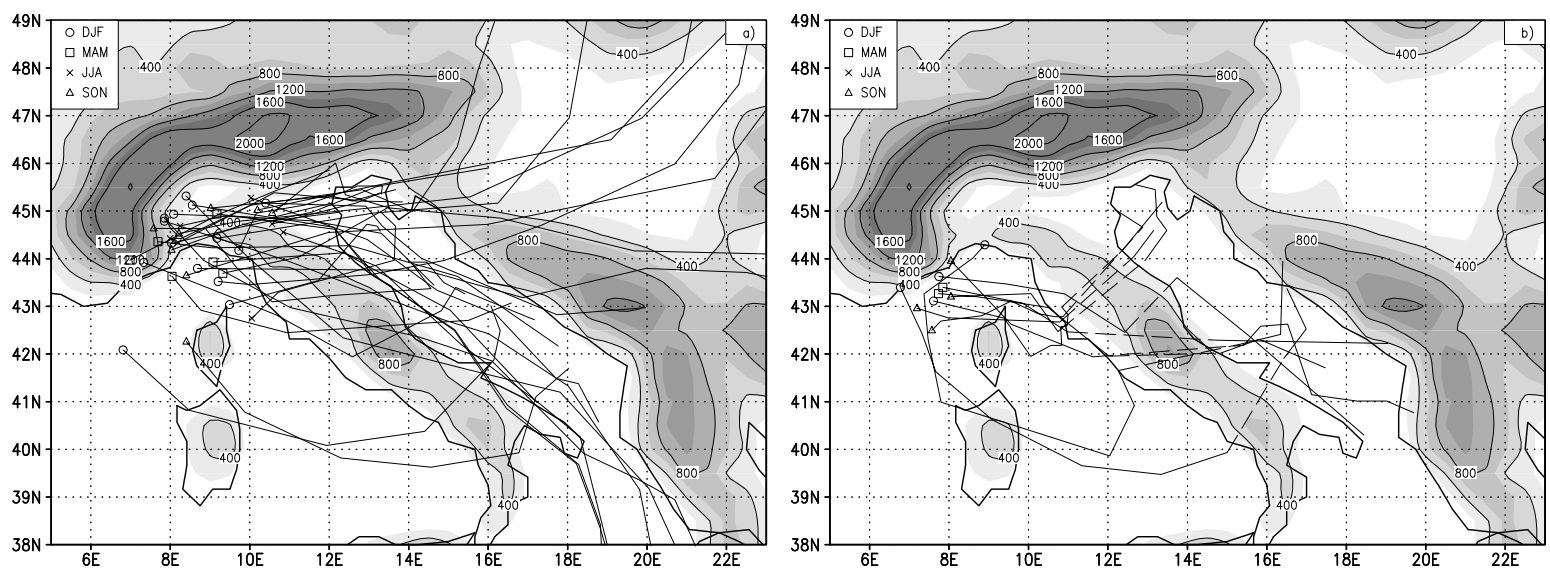

Figure 2.a-b: Track plots of Genoa cyclones. Left: Type A-I continuous. Right: Type A-II discontinuous cyclones. Most of the A-I cyclones cross the Apennine peninsula in the north, whilst most of the A-II cyclones traverse to Adriatic over the middle Apennines.

Based on the selected classification criteria, several types of cyclones that appear in the Adriatic basin and their associated tracks are detected and classified as the following types:

1. A - Genoa cyclones (Gulf of Genoa and northern Italy)

a. A-I - continuous Genoa cyclones

b. A-II - discontinuous Genoa cyclones

2. $\mathrm{B}$ - Adriatic cyclones

a. B-I - northern Adriatic cyclones

b. B-II - middle Adriatic cyclones

3. $\mathrm{AB}$ - both Genoa and Adriatic cyclones exist (twin or eyeglass cyclones)

4. $\mathrm{C}$ - non-Genoa and non-Adriatic cyclones

a. C-I - continuous cyclones

b. C-II - discontinuous cyclones

Most of the cyclones $(\sim 35 \%)$ that appear in the Adriatic are cyclones that originate in the Gulf of Genoa or northern Italy, commonly referred to as Genoa or Alpine lee cyclones and here identified as the Type A cyclones (Fig. 2.a-b). This reflects the fact that in winter the area is the most active cyclogenesis region in the whole western Mediterranean (e.g., Trigo et al., 1999). Indeed, in our study the Genoa cyclones occur in winter (DJF) are twice as frequent as those in other seasons (Table 1). This result resembles the outcome of several subjective studies (e.g. Radinović, 1965, Campins et al., 2000). On the other hand, a number of objective studies (Campins et al., 2006, Maheras et al., 2001) indicated that summer is the main season for Genoa cyclone activity. Thus it seems that deeper winter cyclones steered by the upper level trough have a stronger preference to traverse the Apennine range, whilst shallow summer cyclones are more stationary and

Table 1. Seasonal variability of the cyclone types in the Adriatic region detected in period 2002-2005

\begin{tabular}{|c|c|c|c|c|c|c|c|}
\hline & $\mathrm{A}$ & $\mathrm{AB}$ & $\mathrm{B}-\mathrm{I}$ & $\mathrm{B}-\mathrm{II}$ & $\mathrm{C}-\mathrm{I}$ & C-II & TOTAL \\
\hline DJF & 10 & 3 & 14 & 4 & 14 & 3 & $\mathbf{4 8}$ \\
\hline MAM & 6 & 2 & 6 & 2 & 11 & 2 & $\mathbf{2 9}$ \\
\hline JJA & 11 & 1 & 7 & 0 & 1 & 1 & $\mathbf{2 1}$ \\
\hline SON & 7 & 2 & 8 & 4 & 10 & 1 & $\mathbf{3 2}$ \\
\hline TOTAL & $\mathbf{3 4}$ & $\mathbf{8}$ & $\mathbf{3 5}$ & $\mathbf{1 0}$ & $\mathbf{3 6}$ & $\mathbf{7}$ & $\mathbf{1 3 0}$ \\
\hline
\end{tabular}



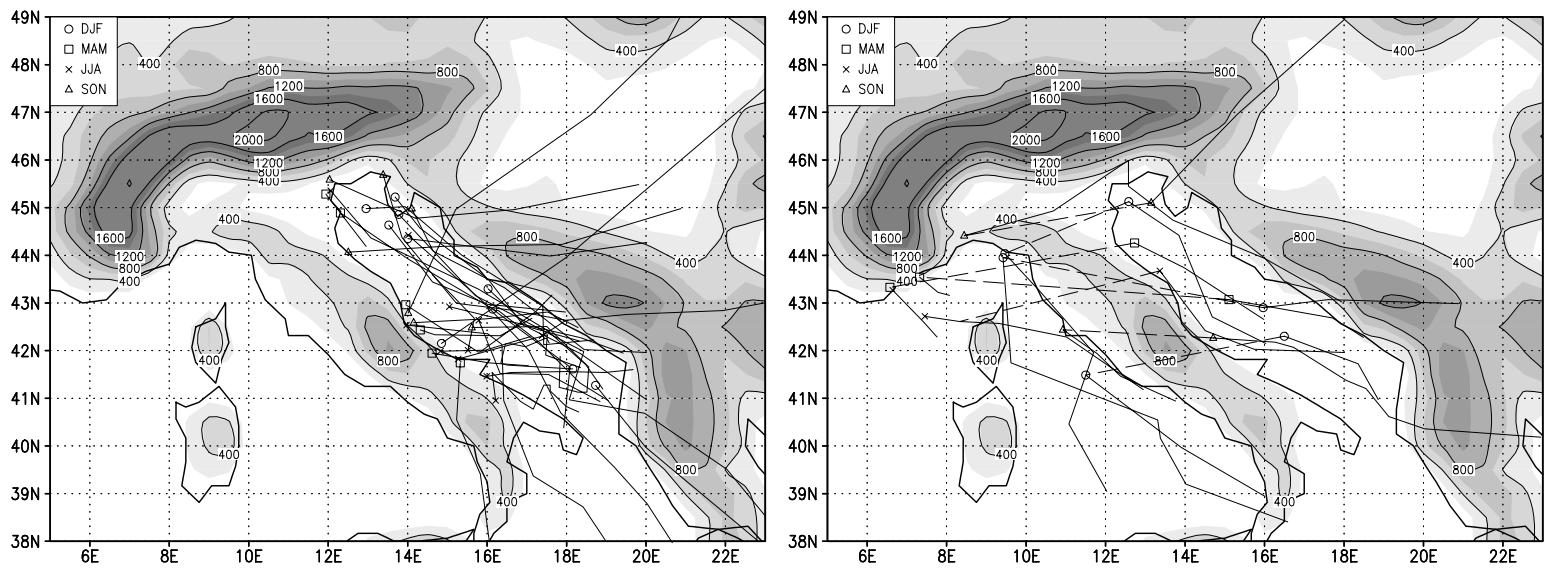

Figure 3.a-b: Left: Type B-I Adriatic cyclones move from north to south along the Adriatic Sea and Type B-II Adriatic cyclones initiate in the lee of Middle Apennines and traverse the Adriatic perpendicular to the main basin axes. Right: Type AB (twin, “eyeglass”) cyclone - two cyclone centres simoultaneously coexist.

have their paths along the western Apennine coast. Two main types of Genoa cyclones that traverse to Adriatic were detected according to the criterion of continuity across the Apennine mountain range. Most of the Genoa cyclones initiate over the lee of the continental Alpine mountain range, close to the Gulf of Genoa, retaining their continuity during the traversal over the peninsula (Genoa A-I type). These cyclones usually cross the northern, lower part of the Apennines along the Po Valley to northern Adriatic where tracks start to diverge (Fig. 2.a).

Occasionally, Genoa cyclones move along the western Italian coast to the Tyrrhenian Sea before traversing to the Adriatic over the higher parts of the Apennines. Such a cyclone track often results in a discontinuous cyclone track with two separate MSLP and circulation centers, present simultaneously on both sides of the mountain. In subsequent development, typically the windward center experiences cyclolysis and the lee center strengthens and eventually replaces the parent cyclone. Although the temporal resolution of the dataset is rather coarse with respect to advection time scale over the mountain, such processes were identified over the Apennines, constituting the Type A-II Genoa cyclones (Fig. 2b). It is anticipated that the number of discontinuous cases would increase with the increase of the time resolution of the reanalysis dataset.

Two major types and tracks of intrinsic Adriatic cyclones (Type B) are detected and contribute to $25 \%$ of the total number of detected cyclones in the region (Table 1). The first subcategory of Type B cyclones (i.e., Type B-I) initiate in the lee of Alps in the northern Adriatic Sea and moves southeastward along the basin
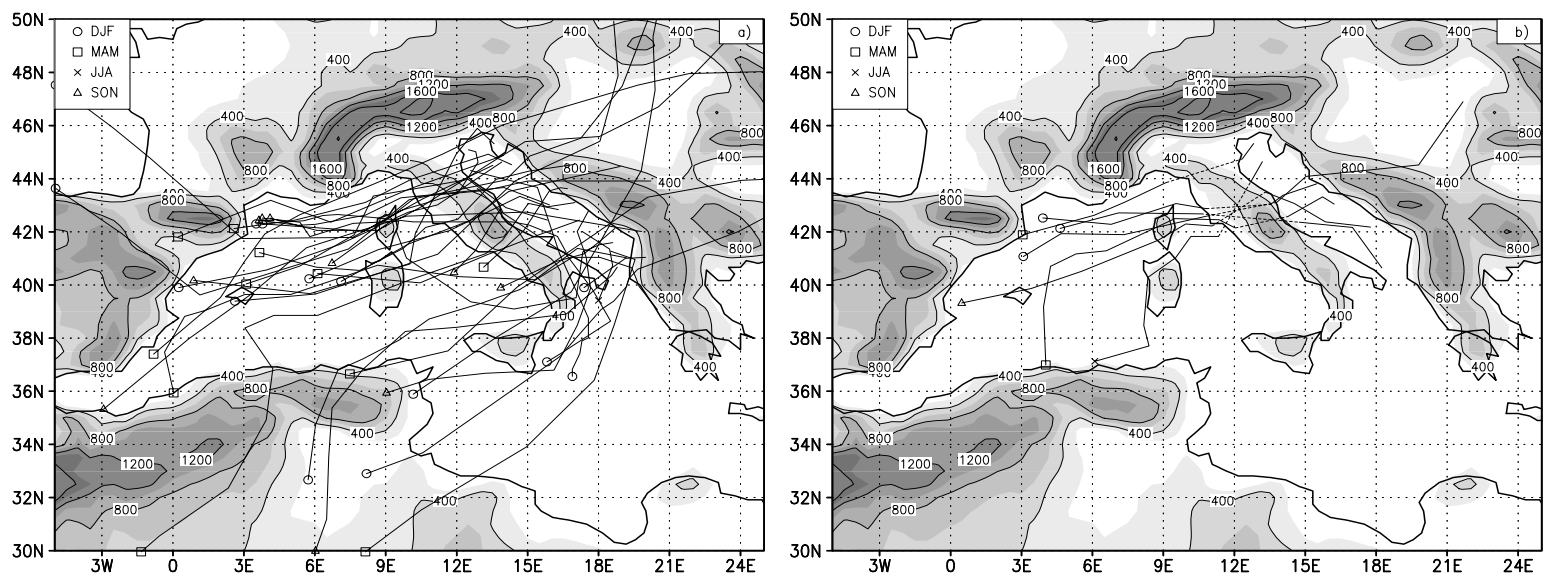

Figure 4.a-b: Track plots of non-Adriatic and non-Genoa cyclones. Left: continuous C-I and Right: discontinuous C-II cyclones. This type of cyclones is initiated in the areas of Pyrenees, Iberia, Atlas, Alboran Sea and Atlantic as well as over the Mediterranean. 
(Fig 3.a). This type of cyclone seems to be qualitatively similar to the Genoa cyclones that move along the western Italian coast over the Tyrrhenian Sea. Most of these cyclones are generated in the colder season of the year.

The second subcategory of Adriatic cyclones (i.e., Type B-II cyclones) originates in the lee of middle Apennines and quickly traverses the Adriatic almost perpendicular to the basin. This type of cyclones has considerably shorter life-time scale and is less intensive than the northern Adriatic type, rarely deepening more then 4-5 hPa throughout their Adriatic life-cycle. For this reason, a well-defined genesis location of type B-II cyclones was not clearly identified in earlier studies. Most of these cyclones occur in the warmer season of the year, what implies that beside orographic effect, heat fluxes from the sea might be strong cyclogenetic factors.

Occasionally, two cyclones simultaneously exist, one over the Gulf of Genoa and the other over the northern or middle Adriatic Sea. These cyclones are called Twin or Eyeglass cyclones in the literature (e.g. Brzović, 1999) and are classed as Type AB in this study (Fig. 3.b). In average, this type of rather rare events occurs less than twice yearly.

Non-Adriatic and non-Genoa type cyclones are classified as Type $\mathrm{C}$ cyclones, which are initiated further to the west (Fig. 4.a-b). These cyclones are initiated in several cyclogenesis areas of western Mediterranean, such as Pyrenees, Iberia, Atlas, Alboran Sea and Atlantic, as well as over the Mediterranean water mass. They contribute to about $35 \%$ of the total number of cyclones detected in the Adriatic area.

Similar to Genoa cyclones, the majority of type $\mathrm{C}$ cyclones cross the Italian peninsula to Adriatic Sea with no significant signs of discontinuity (Type C-I, Fig. 5a). However, some Type C cyclones become discontinuous and experience redevelopment over the Apennine mountain range (Type C-II, Fig. 5b). The apparent lack of Type $\mathrm{C}$ cyclones in the Adriatic in summer might imply that shallow thermal Iberian cyclones may not protrude to Adriatic due to lack of upper-level steering and predominant westerly and northwesterly summer winds over the Gulf of Genoa and Tyrrhenian and Adriatic Sea regions.

\section{CONCLUSIONS}

Cyclone types identified include cyclones that initiated in the Gulf of Genoa (Type A), Adriatic (Type B), both Genoa and Adriatic simultaneously (Type $A B$ ) and cyclones that originated elsewhere (Type C). In addition, cyclones that traversed the Apennine peninsula were classified based on their continuity on the Apennine range (for Type A and Type C cyclones). Most of the cyclones in the Adriatic are Genoa cyclones $(\sim 35 \%)$ and Type $\mathrm{C}$ cyclones $(\sim 35 \%)$. However, this study identified a significant number of intrinsic Adriatic cyclones $(\sim 25 \%)$, that were not well recognized in synoptic scale studies due to their meso- $\beta$ dimensions, and low depths (4-5 hPa).

In future work, this climatology study and the presented cases will serve as a platform for the analysis of precipitation patterns of different cyclone tracks in the Adriatic as well as a background for numerical modelling and analysis, being a tool for understanding the dynamical and physical properties of the Adriatic cyclones.

Acknowledgements: The authors would like to thank Ministry of Science, Education and Sports of Republic of Croatia for the support under the project number 0004001 and a student scholarship grant (K. Horvath). Partial support of NSF under Grant ATM-0096876 is appreciated.

\section{REFERENCES}

Brzović, N., 1999: Factors affecting the Adriatic cyclone and associated windstorms. Contr. Atmos. Phys., 72, 51-65.

Campins J., A. Genovés, A. Jansà, J. A. Guijarro, and C. Ramis, 2000: A catalogue and a classification of surface cyclones for the Western Mediterranean. Int. J. Climatol., 20, 969 - 984.

Campins, J., A. Jansà, and A. Genovés, 2006: Three-dimensional structure of western Mediterranean cyclones. Int. J. Climatol., 26, 323-343.

Maheras P., H. A. Flocas, I. Patrikas, and C. Anagnostopoulou, 2001: A 40 year objective climatology of surface cyclones in the Mediterranean region: spatial and temporal distribution. Int. J. Climatol., 21, 109-130.

Radinović, D., 1965: Cyclonic activity in Yugoslavia and surrounding areas. Arch. Met. Goeph. Biokl. A 14, $392-408$.

Trigo I. F., D. Trevor, H. C. Davies, and G. R. Bigg, 1999: Objective Climatology of Cyclones in the Mediterranean Region. J. Clim., 12., Issue 6, 1685-1696. 